\title{
NEPAL'S BUMPY TRANSITION TO FEDERALISM: IMPLICATIONS FOR THE HEALTH SYSTEM
}

\author{
Rushton $\mathrm{S}^{1}$ Ghimire $\mathrm{S}^{2}$ Marahatta $\mathrm{SB}^{3}$ \\ ${ }^{1}$ Department of Politics, University of Sheffield, UK; \\ ${ }^{2}$ Department of Health Education, Tribhuvan University, Nepal \\ ${ }^{3}$ Department of Public Health, Manmohan Memorial Institute of Health Sciences, Nepal / \\ Managing Editor JMMIHS
}

In spite of protracted political instability since the restoration of democracy in 1990, Nepal has made remarkable progress in the development of its health system, services and their coverage, with notable improvements in the health outcomes and wellbeing of the people. These gains have mainly been due to substantial increases in health financing and human resources for health - mainly doctors, nurses, midwives and other paramedical workers - and their mobilization around the Millennium Development Goals (MDGs). The health gains achieved by the country during the first 15 years of the new millennium were particularly remarkable if we consider the resource constraints Nepal faced, and the fact that the country experienced a civil war for the first six years of that period.

Even so, the current health situation is far from acceptable. The health gains have not been evenly distributed across the population, leading to huge geographical and socio-economic disparities. The implementation of a new constitution, with a new federal governance structure and new local bodies, offers an opportunity to reform the existing health system to address these disparities, to achieve the aim of Universal Health Coverage, and to deliver on the constitution's guarantee of the right to health for all citizens.

In their editorial in this journal (JMMIHS) last year, Padam Simkhada and colleagues noted that Nepal's health system was "undergoing some very interesting radical reforms." In the time since that editorial was published, the reform process has only become more interesting. As Simkhada and colleagues rightly noted, the shift from a highly centralised health system to a more decentralised model aligned with Nepal's new federal system was dramatically affecting both the structure and operation of the health system. As the implementation of the new federal structure, including Provincial-level governments who now have the lead responsibility for health service delivery, has rolled out, some problems have started to become apparent. Recent conversations with health policymakers in Nepal have highlighted a 
range of concerns, and the need for some urgent actions to be taken by authorities at all levels to ensure that the decentralisation of the health system leads to positive rather than negative changes.

Some degree of bureaucratic turmoil would be expected in any country undergoing such a major restructuring of its government arrangements. Such turmoil is certainly in evidence in the health system.

For one thing, staffing the new Provincial governments has been a challenge. Central level departments have lost staff. Previous personal relationships, which aided in communication between sections and departments, have been disrupted. On a personal level, many staff are uncertain and worried about their future - waiting to hear whether they will be moved from Kathmandu to one of the new provincial capitals. Such teething troubles are an understandable part of such a major administrative transition and will, it is hoped, settle down with time.

Perhaps more worryingly, many people involved in the health system have also reflected on a lack of clear lines of responsibility within and between levels of government and imperfect understandings of the roles and functions of each component at each level. Nepal's previously clear health system organogram, which stretched from the Ministry in Kathmandu right down to the village health post, is now far less clear. Municipal and Provincial governments are up and running, but Districts are still operating. Communication between these levels is not always as smooth as it might be. To take one example, in the area of disease surveillance (an area in which the need for national coordination is obvious), some of our respondents noted a lack of knowledge in some Provinces about who to call if and when an outbreak happens - and where that call is made, the reporting often relies on pre-existing personal networks rather than a clear administrative line of reporting.

To further complicate this situation, there are real sensitivities around the relationships between levels of government. On the one hand, those working in the central government talk about the need for better coordination and more consistency across the country. On the other, such people are reluctant to be seen as 'centralisers' who could be viewed as undermining the political project of federalisation. Meanwhile, provinces and local governments are keen to be seen to be delivering services (not least for electoral reasons), but this can create a 
tendency to resist attempts to introduce national-level coordination and cooperation, which could be interpreted as handing power back to Kathmandu.

Many countries have previously decentralised their health systems - albeit with varying degrees of success. However, there is an interesting dynamic at work in the federalisation of the health system in Nepal that sets it apart from the experiences of other countries. Generally, health system decentralization efforts elsewhere have been driven by two desires: the desire to improve the efficiency of service delivery; and the desire to bring decisionmaking closer to the people. In Nepal we see a different driver of federalisation: a political decision to move to a federal system, in large part a product of the country's peace process, to which the health system must adapt. The health system is affected by, but is not itself driving, decentralisation.

Federalisation is not, of course, responsible for all of the difficulties that Nepal's health system faces. There were already many problems, from health worker absenteeism to infrastructure deficiencies to medicine shortages - and much more. There may indeed be new opportunities opened up as a result of the new political structure - including the efficiencies and public participation in decision-making that have been pursued in other countries.

It is already clear, however, that for the positives of federalisation to be captured and the negatives avoided, some important actions need to be taken quickly. Terms of reference and lines of reporting need to be clarified. New legislation (including the new Public Health Act) needs to be enacted and implemented. Capacities (in terms of human resources as well as infrastructure, equipment and systems) need to be further developed at sub-national government levels. Staffing issues need to be overcome. And all of this must be done in addition to addressing the problems that Nepal's health system has faced for so long.

The majority of these challenges are not technical: they are political and bureaucratic. Effective and informed leadership at all levels of government will be needed to overcome them. Successfully doing so will not only affect health service delivery today and tomorrow, but could have a positive effect on the health of the people of Nepal for generations to come. 